\title{
Scan preparation for patients with type I diabetes treated with continuous sub-cutaneous insulin infusion (CSII) pumps
}

\author{
Bernd Krause $^{1} \cdot$ Sally Barrington ${ }^{2}$ (ID $\cdot$ lain Cranston ${ }^{3}$
}

Received: 20 June 2019 / Accepted: 2 July 2019 / Published online: 23 July 2019

(C) Springer-Verlag GmbH Germany, part of Springer Nature 2019

\section{To the Editor}

It has come to our attention that the guidance about scan preparation for patients with type I diabetes in the European Association guideline for tumour imaging with FDG PET [1] contains a statement relating to management of individuals on 'insulin pumps' which may result in risk for some patients with type 1 diabetes undergoing imaging.

Individuals with type 1 diabetes treated with continuous sub-cutaneous insulin infusion (CSII) pumps are best managed by undertaking the scan early in the morning with the pump running on basal insulin rates alone to maintain euglycemia. In particular, such individuals should NOT discontinue the basal infusion as per the original text, as this creates a significant ketosis $( \pm$ ketoacidosis) risk. Individuals in hospital using intravenous insulin delivery (usually as part of a combined insulin + dextrose + potassium infusion) are best managed by delaying their scan until such intravenous therapy is no longer required or (if urgent) by consultation with the local diabetes specialty team for individual advice.

Yours faithfully on behalf of all authors.

Bernd Krause, Sally F Barrington and Iain Cranston.

This article is part of the Topical Collection on Letter to the Editor

Sally Barrington

sally.barrington@kcl.ac.uk

1 Department of Nuclear Medicine, University Medical Centre, Rostock, Germany

2 KCL and Guy's and St Thomas' PET Centre, School of Biomedical Engineering and Imaging Sciences, King's College London, Kings Health Partners, 4th floor Lambeth Wing, Westminster Bridge Road, London SE1 7EH, UK

3 Department of Diabetes and Endocrinology, Portsmouth Hospitals NHS Trust, Portsmouth P6 3LY, UK
Funding Professor Barrington acknowledges support from the National Institute for Health Research and Social Care (NIHR) [RP-2-16-07-001]. King's College London and UCL Comprehensive Cancer Imaging Centre is funded by the CRUK and EPSRC in association with the MRC and Department of Health (England). The views expressed are those of the author(s) and not necessarily those of the NHS, the NIHR, or the Department of Health.

\section{Compliance with ethical standards}

Conflict of interest None of the authors have any conflicts of interest to declare.

Ethical approval This article does not contain any studies with human participants or animals performed by any of the authors.

\section{Reference}

1. Boellaard R, Delgado-Bolton R, Oyen WJ, Giammarile F, Tatsch K, Eschner W, et al. FDG PET/CT: EANM procedure guidelines for tumour imaging: version 2.0. Eur J Nucl Med Mol Imaging. 2015;42(2):328-54. https://doi.org/10.1007/s00259-014-2961-x.

Publisher's note Springer Nature remains neutral with regard to jurisdictional claims in published maps and institutional affiliations. 